\title{
Investigating the Factors Influencing the Decoupling of Transport-Related Carbon Emissions from Turnover Volume in China
}

\author{
Xue-ting Jiang ${ }^{1,2,3, *}, \mathrm{Min} \mathrm{Su}^{4}$ and Rongrong $\mathrm{Li}^{4}$ \\ 1 State Key Laboratory of Desert and Oasis Ecology, Xinjiang Institute of Ecology and Geography, \\ Chinese Academy of Sciences, Urumqi 830011, China \\ 2 CAS Research Center for Ecology and Environment of Central Asia, Chinese Academy of Sciences, \\ Urumqi 830011, China \\ 3 College of Resources and Environment, University of Chinese Academy of Sciences, Beijing 100049, China \\ 4 School of Economic \& Management, China University of Petroleum (East China), \\ No. 66 West Changjiang Road, Qingdao 266580, China; minsu201703@126.com (M.S.); lirr@upc.edu.cn (R.L.) \\ * Correspondence: jiangxueting16@mails.ucas.ac.cn; Tel.: +86-0532-8698-1324
}

Received: 10 July 2018; Accepted: 15 August 2018; Published: 27 August 2018

\begin{abstract}
With the boom of vehicles, especially the dramatic rise of private car ownership, in China, transport $\mathrm{CO}_{2}$ emission in China has surged. However, China has been taking the responsibility to cut down carbon emissions and to make positive efforts towards technology innovations in the transport sector. Breaking the link between transport carbon emissions and transport turnover capacity for the past decades should be analyzed. The paper tested the decoupling degree and ranked its potential determinants for every transport mode in consideration of specific transport mode characteristics. We extended the original Kaya identity to make the factor analysis more pertinent to the analysis of transport-related $\mathrm{CO}_{2}$ emissions. Besides, we combined the decomposition technique with decoupling analysis, decomposing the transport decoupling index into five distinct aspects to detect the key drivers of the decoupling of transport-related $\mathrm{CO}_{2}$ emissions from transport turnover volume. Moreover, we analyzed the relationship between transport-related $\mathrm{CO}_{2}$ emission and transport output, which also offers a novel perspective on transport and corresponding environmental research. The results uncovered that a weak decoupling state appeared between 1990-1995 and 2000-2010 in China's transport sector. Transport energy efficiency exerted the most significant impact in accelerating the decoupling of transport-related $\mathrm{CO}_{2}$ emissions from turnover volume for all transport modes while the energy mix effect impeded the decoupling evolution in most observed periods. Railway transport turnover and rail locomotives shared rises boosted by decoupling evolution, while vehicular transport showed adverse effects. The rise of the transport facilities' shares of railways, waterways, and airways also advanced the decoupling evolution. Hence, policies of switching travel modes and establishing a "smart growth" pattern for private vehicles should be considered.
\end{abstract}

Keywords: transport sector; mode decoupling analysis; transport turnover volume; China

\section{Introduction}

$\mathrm{CO}_{2}$ emission mitigation has become a widely discussed topic in the last decades. The transport sector in China has drawn more attention with the development of its transport system. The current state and the relevant environmental issues of the transport sector in China have gained worldwide attention. According to the International Energy Agency (IEA), transport in China was the fastest growing sector for $\mathrm{CO}_{2}$ emissions between 1990 and 2015, with a change rate of $656 \%$ [1]. For decades, 
the transport sector has generally been considered as a carbon emission booster. To this end, we tried to figure out whether it would be possible for transport turnover volume to increase with a simultaneous decrease in $\mathrm{CO}_{2}$ emissions. Consequently, research on the possibility and level of decoupling of carbon emissions from transport turnover volume was carried out. Detecting the main influencing factors of China's transport carbon emissions provides reference for policy makers to slow emission growth or cut emissions without impeding the gains in transport turnover. China has been making positive efforts to reduce its carbon emissions [2]. Besides the international mitigation task, domestic strategies, such as establishing the largest carbon trading market [3] have also been recently adopted. Meanwhile, transport capacity has increased, for instance, passenger turnover has grown more than four times since 1990 (562.84 billion passenger $\mathrm{km}$ in 1990 to 3005.89 billion passenger-km in 2015). Thus, decoupling of transport-related $\mathrm{CO}_{2}$ emissions from turnover volume in China should be discussed.

\subsection{Literature Review of Decoupling Analysis for the Transport Sector}

The debate on decoupling between environmental changes and the issues of social-economic systems is becoming a hot issue nowadays. The decoupling of increasing economic or sectoral output from the growth of carbon emissions has spurred much research [4-8]. The idea and concept of decoupling was firstly proposed by Von in 1989 [9]. Zhang introduced the decoupling method to analyze the relationship between carbon emissions and economic growth in China and sought feasible win-win strategies [10]. The OECD advanced the method into an analysis tool to discuss the relationship between carbon emissions and economic growth [11]. After that, many studies on decoupling and evolution were carried out. Tapio [12] identified eight decoupling possibilities to develop the decoupling system by advancing the decoupling elasticity indicator. These decoupling states offered distinguishing connections between environmental changes and economic gains, mainly from coupled, decoupled, or negatively decoupled aspects. Also, a 20\% tolerance interval was defined to eliminate the changes from slight variation. Diakoulaki and Mandaraka [13] performed decoupling analysis by incorporating the decomposition method to give a more specific interpretation of the influencing mechanisms of the European Union's manufacturing sector's carbon emissions from added industrial value. Loo and Banister [14] analyzed the decoupling relationship of transport from economic growth by covering carbon emission issues and economic dimensions. Alises et al. [15] aimed to investigate the decoupling evolution of road turnover and GDP of two typical countries in the European Union: the UK and Spain, to promote policy development towards of decoupling of road freight transport demand and economic growth. However, most decoupling analyses have been aimed at figuring out the connection between the environment and economic gains from industries or specific sectors (GDP or the added economic value of an industry). A few studies have focused on the sectoral output from the specific perspective of the transport sector, instead of the transport economic added value. So, we investigated the relationship between $\mathrm{CO}_{2}$ emission and transport turnover ability by calculating the decoupling indices of different transport modes in various years.

Some researchers have calculated carbon emissions resulting from transport. He et al. [16] made a calculation of carbon emissions from road freight and passengers. Loo and Li [17] estimated carbon emissions of passenger transport in China between 1949 and 2009 and identified the spatial disparity from the provincial level by applying a distance-based method and a fuel-based method.

Most previous studies have focused on the decoupling analysis of carbon emissions and economic indices, such as gross domestic product (GDP). However, in the transport sector analysis, few studies considered whether carbon emission mitigation and transport capacity improvement can be achieved at the same time. In other words, can the rigid and long-existing link between carbon emission increase and transport capacity improvement be cut?

We aimed to investigate the potential determinants of transport carbon emissions by combining the decomposition technique from the perspective of transport sector characteristics by calculating the decoupling indices of different travelling modes. Moreover, apart from the traditional energy consumption or fuel type analysis, we discussed the carbon emission decoupling possibilities from 
different transport modes. When analyzing the influencing factors of decoupling status changes, private car ownership and passengers' travelling options are also included in our research. We analyzed the potential influencing factors of the decoupling process, mainly from the following aspects: energy mix effect, transport energy efficiency effect, transport facility share effect, transport usage effect, transport turnover mix effect. So, the strategies and policies concerning the modes can be correspondingly developed or adjusted.

To make sure it could reveal the mechanism of transport modes with distinct characteristics, the decoupling analysis was conducted in line with the main passenger and freight modes, by analyzing the decoupling degree and factor contribution as well as ranking the determinants. This paper aimed to elucidate the relationship between $\mathrm{CO}_{2}$ emissions from fuel combustion and the transport output gains. Our findings not only offer policy adjustment suggestions for transition of the whole transport system and technology improvement, but also give some beneficial information for strategy development or improvement for other countries. Moreover, our analysis was applied to uncover the response and synchronization level of the environmental changes and the sectoral output gains of different years.

\subsection{Literature Review of Factor Detection Analysis for the Transport Sector}

Various studies on driver analysis of energy use and the corresponding environmental impacts, such as greenhouse gas (GHG) emission, have been carried out from different angles via different methods in recent decades [18-21]. In general, three main types of methods are widely used: decomposition analysis, the econometric technique, and system optimization.

The decomposition technique is based on the IPAT model [22] and Kaya identity [23]. The IPAT model $\left(I=P^{*} A^{*} T\right)$ was first proposed in 1971 and was then developed into the stochastic impacts by regression (STIRPAT) model by Dietz and Rosa [24] and then modified to the STIRPAT model [24] to overcome some factors analysis limits of the IPAT model. Since then, many studies on transport sectors were based on the IPAT identity. However, among various decomposition methods, the two most widely used are index decomposition analysis (IDA) and structural decomposition analysis (SDA). The SDA approach was developed from an input-output (I-O) table. The I-O based analysis was first extended into environment studies [25]. Rose and Casler [26,27] reviewed the development of SDA and its connection with other methodologies and presented the principles of alternative approaches and other decomposition methods originating from Input-Output tables. Dietzenbacher and Los [28] discussed the problems caused by the various decomposition methods used to measure the contribution of a specific determinant. After that, Su and Ang [29] reviewed the new development of SDA concerning energy studies and provided guidelines on decomposition method selection for SDA after discussing the similarities and differences between SDA and IDA by summarizing the latest related studies.

The econometric technique is also a widely applied tool for transport sector analysis. Graham et al. [13] applied a dynamic panel model to identify the contribution of income, fares, and quality of service to demand. Liao et al. [30] analyzed the $\mathrm{CO}_{2}$ emissions of container transport and reported the main drivers via a multiple regression model. Zhang et al. [31] discussed China's $\mathrm{CO}_{2}$ emissions in the transport sector using the STIRPAT model and provincial panel data. Many studies were also carried out by the system optimization method. Paravantis and Georgakellos [32] analyzed $\mathrm{CO}_{2}$ emissions and six factors from passenger cars and buses via developed aggregate car ownership and bus fleet models. Shakya and Shrestha [33] discussed the effects of transport sector electrification on environmental emissions under five different levels for the road transport system in Nepal.

These studies on transport sectors paid more attention to energy consumption and related carbon emission. However, if the rigid link between transport carbon emission and turnover volume can be broken, the reasons that cause the decoupling need to be clarified. The econometric technique mainly focuses on figuring out the contribution of each factor. However, when comparing the decoupling contribution of each influencing factor, the $\mathrm{CO}_{2}$ emission should be quantified. So, we attempted to 
apply the decomposition method to identify the main drivers and the contribution of each factor in the decoupling of carbon emissions from transport turnover volume.

In recent studies of the transport sector, driver detection analysis has primarily focused on energy consumption, energy intensity, and greenhouse gases emission [34,35]. We summarized key examples of decomposition analysis of transport sectors in Table 1. To be more specific, Scholl et al. [36] gave an analysis of the main drivers of transport-related $\mathrm{CO}_{2}$ emissions in nine OECD countries with the factors of passenger activity, modal structure, transport energy and intensity, and fuel mix. Papagiannaki and Diakoulaki [37] discussed the drivers of vehicles per capita, average distance traveled by car, and the shares of cars. Achour and Belloumi [38] decomposed the drivers of the Tunisian transportation sector's energy consumption via applying the logarithmic-mean Divisia index (LMDI) method and found that except for energy intensity, all other factors were positive in increasing energy consumption. They reached the conclusion that energy intensity should be the focus of policy measures to decrease transport-related carbon emission in Tunisia. Feng et al. [39] discussed sectoral GHG emission in China from consumption and income perspectives via the SDA model and analyzed the main drivers of GHG emissions on the basis of consumption and income metrics. Luo et al. [40] tried to provide critical insights and practical guidance to low-carbon urban planning in developing countries by comparing the driving factors of urban transport-related $\mathrm{CO}_{2}$ emissions in Shanghai and Tokyo. Their research illustrated the driver analysis of two Asian mega cities' urban transport carbon emissions. Edelenbosch et al. [41] applied Laspeyres index decomposition method to compare results across models and scenarios when analyzing passenger transport. Andrés and Padilla [42] identified key influencing factors of GHG emissions from European Union transport activities by analyzing the factors of population, economic activity, transport volume, and the structural characteristics of transport activity. Although, previous studies have mainly analyzed transport-related $\mathrm{CO}_{2}$ emissions or the drivers of carbon emission changes, few of them quantified the contribution of each influencing factor to the decoupling from the transport turnover ability. Therefore, whether the link between carbon emission and transport turnover volume can be broken and how this could happen should be clarified.

Based on this, we will try to fill the gap by decomposing the carbon emission decoupling index of turnover volume.

The rest of the paper is structured as follows: Section 2 contains the materials and methods; Section 3 details the results; Section 4 details the conclusion; and Section 5 offers conclusions and policy implications.

Table 1. Literature on the decomposition analysis of the transport sector.

\begin{tabular}{|c|c|c|c|c|}
\hline Authors and Year & Region & Period & Decomposition Subjects & Drivers \\
\hline Schipper et al. (1992) [43] & 8 OECD countries & 1970-1987 & energy use, passenger & $\begin{array}{l}\text { total travel volume, modal energy } \\
\text { intensities, mode shares, vehicle activity, } \\
\text { load factor, energy intensity }\end{array}$ \\
\hline Scholl et al. (1996) [36] & 9 OECD countries & 1973-1992 & $\mathrm{CO}_{2}$ emission, passenger & $\begin{array}{l}\text { activity, structure, } \mathrm{CO}_{2} \text { intensity, energy } \\
\text { intensity, and fuel mix }\end{array}$ \\
\hline $\begin{array}{l}\text { Greening et al. } \\
\text { (1999) [46] }\end{array}$ & 10 OECD countries & 1971-1993 & carbon intensity, freight & $\begin{array}{l}\text { primary fuel emissions rate, sectoral fuel } \\
\text { use share, sectoral energy intensity share, } \\
\text { modal mix }\end{array}$ \\
\hline Kwon (2005) [47] & Great Britain & 1970-2000 & $\mathrm{CO}_{2}$ emission, car travel & $\begin{array}{l}\text { population, per-capita consumption, and } \\
\text { environmental impact per quantity } \\
\text { of consumption }\end{array}$ \\
\hline
\end{tabular}


Table 1. Cont.

\begin{tabular}{|c|c|c|c|c|}
\hline Authors and Year & Region & Period & Decomposition Subjects & Drivers \\
\hline $\begin{array}{l}\text { Sobrino and Monzon } \\
\text { (2014) [48] }\end{array}$ & Spain & 1990-2010 & GHG emission, road transport & $\begin{array}{l}\text { traffic activity, fuel economy and } \\
\text { socioeconomic development }\end{array}$ \\
\hline $\begin{array}{l}\text { Achour and Belloumi } \\
\text { (2016) [38] }\end{array}$ & Tunisian & 1985-2014 & energy consumption, transport & $\begin{array}{l}\text { energy intensity, transportation structure } \\
\text { effect, transportation intensity effect, } \\
\text { economic output, and population } \\
\text { scale effects }\end{array}$ \\
\hline Feng et al. (2017) [39] & China & 1995-2009 & GHG emissions & $\begin{array}{l}\text { GHG intensity, production structure, final } \\
\text { demand structure, and final } \\
\text { demand volume }\end{array}$ \\
\hline Luo et al. (2017) [40] & Shanghai and Tokyo & 1986-2009 & $\mathrm{CO}_{2}$ emission, urban transport & $\begin{array}{l}\text { trip generation, mode shift, and } \\
\text { technology level }\end{array}$ \\
\hline $\begin{array}{l}\text { Edelenbosch et al. } \\
\text { (2017) [41] }\end{array}$ & World & $2010-2100$ & $\mathrm{CO}_{2}$ emission passenger transport & $\begin{array}{l}\text { population, activity growth, modal } \\
\text { structure, energy intensity, and fuel mix }\end{array}$ \\
\hline
\end{tabular}

\section{Materials and Methods}

\subsection{Methods}

We drew a flow chart of modeling concepts and methodologies to demonstrate the modeling concepts clearly (Figure 1).

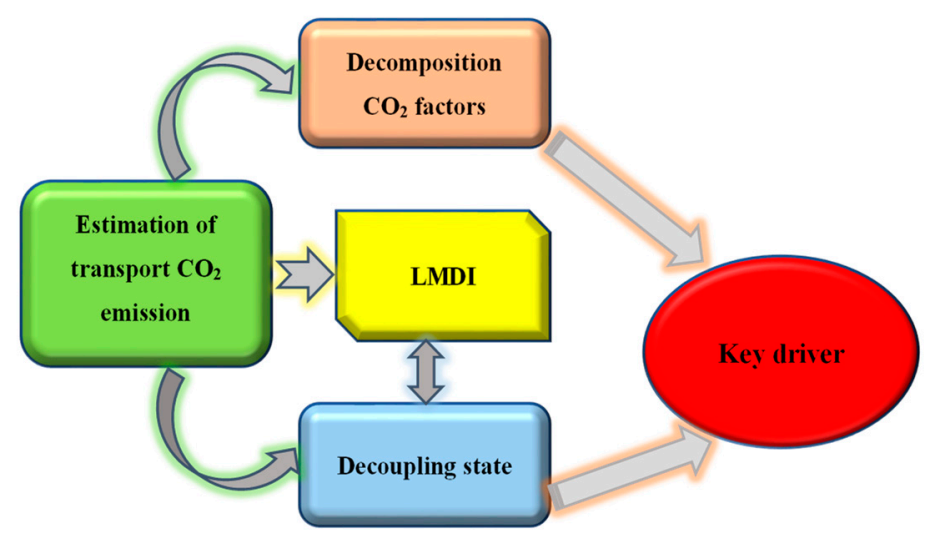

Figure 1. Flow chart of modeling concepts and methodologies.

\subsubsection{Transport Energy-Related $\mathrm{CO}_{2}$ Emission Estimation}

Energy-related $\mathrm{CO}_{2}$ emissions from the transport industry can be calculated by the technique proposed by Intergovernmental Panel on Climate Change (IPCC) [49], the method is shown in Equation (1),

$$
C=\sum\left(C_{i}\right)=\sum\left(E_{i} * \alpha_{i} * O_{i} * m\right)=\sum\left(E_{i} * C F_{i}\right)
$$

where $C_{i}$ (million tons $\mathrm{CO}_{2}$ emission, $\mathrm{Mt} C$ ) and $E_{i}$ (million tons of coal equivalent, Mtce) denote the carbon emission and energy consumption of fuel. $i, \alpha_{i}$, and $O_{i}$ represent the standard carbon emission factor coefficient and the oxidation rate of fuel $i ; m$ is a constant with the numerical value of 44/12 (the molecular weight of $\mathrm{CO}_{2}$ divided by the atomic weight of the element carbon). $C F_{i}$ is $\mathrm{CO}_{2}$ emission coefficient, and the value of each fuel used in this paper were shown in Table 2. In this research, coal, oil, and natural gas were considered as three kinds of fuels and the energy consumption has been converted to million tons coal equivalent (Mtce). 
Table 2. The carbon emission coefficient from fuel consumption in China.

\begin{tabular}{ccccc}
\hline & Fuel Type & Coal & Oil & Gas \\
\cline { 2 - 5 } & Emission coefficient (unit: Mt C/Mtce) & 0.7476 & 0.5825 & 0.4435 \\
\cline { 2 - 3 } Source: National Development and Reform Commission (NDRC) [50] and Chinese Academic Sciences [51].
\end{tabular}

\subsubsection{Transport Decoupling Indices}

Kaya [23] originally proposed multiplicative identities from population, gross domestic product (GDP) per capita (GDP/population), energy intensity (energy consumption/GDP), and $\mathrm{CO}_{2}$ emission coefficient $\left(\mathrm{CO}_{2}\right.$ emission/energy consumption). Based on this decomposition method, we extend the original model to improve its pertinence for discussing transport-related $\mathrm{CO}_{2}$ emission and the possibility of its decoupling from transport turnover volume. The possible influencing factors from the perspective of the Chinese transport sector can be obtained, and the factors are shown in Equation (2).

$$
\begin{gathered}
C=\sum\left(C_{i j}\right)=\sum\left[\left(\frac{C_{i}}{E_{i}}\right) *\left(\frac{E_{i}}{E}\right) *\left(\frac{E}{N}\right) *\left(\frac{N}{N_{j}}\right) *\left(\frac{N_{j}}{T V_{j}}\right) *\left(\frac{T V_{j}}{T V}\right) * T V\right] \\
=\sum\left(E C_{i} * E M_{i} * T E * T S_{j} * T U_{j} * T M_{j} * T V\right)
\end{gathered}
$$

$E$ (Mtce) and $N$ denote the energy consumption and the amount of the transport facilities; $N_{j}$ and $T V_{j}$ (ton-km, moving one ton of goods $1 \mathrm{~km}$ ) represent the amount of transport and the turnover volume of the transport mode $j . E C_{i}\left(\mathrm{CO}_{2}\right.$ emission coefficient, $\left.\frac{C_{i}}{E_{i}}, \mathrm{Mt} C / \mathrm{Mtce}\right)$ and $E M_{i}$ (transport energy mix, $\left.\frac{E_{i}}{E}, \%\right)(i=1,2,3$ measures fuel coal, oil and gas) denote the carbon emission coefficient of fuel $i$ and the energy mix of the transport energy consumption, respectively. TE (transport efficiency, $\frac{E}{N}$, Mtce/per unit) can be defined as the energy consumption in the transport sector divided by the total amount of transportation, revealing the transport efficiency; $T S_{j}$ (transport share, $\frac{N}{N_{j}}, \%$ ) uncovers the transport share of the transport mode $j(j=1,2,3,4$ stands for the mode of railways, airways waterways and highways); $T U_{j}$ (transportation facility usage, $\frac{N_{j}}{T V_{j}}$, units/ton-km) shows the transportation facility usage with per transport turnover volume added in a specific mode. $T M_{j}$ (transport turnover mix, $\left.\frac{T V_{j}}{T V}, \%\right)$ is the turnover mix of transport sector and $T V$ (ton- $\mathrm{km}$ ) denotes the transport turnover volume and the output of the transport sector, respectively.

It should be noted that the transport turnover volume in this paper is measured by the unit of ton- $\mathrm{km}$. The passenger turnover unit of passenger-trip has been converted into the freight measurement of ton-km. By applying Equation (3), the passenger turnover volume can be converted. According to Zhang et al. [42], the conversion coefficient we used is shown in Table 3.

$$
T V_{j}=\frac{T V_{j, 1}}{C O}+T V_{j, 2}
$$

where $T V_{j, 1}$ (per person-km, moving one person $1 \mathrm{~km}$ ) and $T V_{j, 2}($ ton- $\mathrm{km})$ denote the transport turnover volume from the passenger and freight of mode $j$; $C O$ stands for the conversion coefficient of turnover volume to ton- $\mathrm{km}$.

Table 3. The conversion coefficient of turnover volume to ton-km.

\begin{tabular}{ccccc}
\hline Transport Mode & Highways & Railways & Waterways & Airways \\
\hline Conversion coefficient & 5 & 1 & 3.03 & 13.88 \\
\hline
\end{tabular}

To further quantify the contribution of each influencing factor to $\mathrm{CO}_{2}$ emission decoupling from transport turnover volume, the decoupling index can be advanced by combining with the traditional logarithmic-mean Divisia index (LMDI) technique. Since the emission coefficient effect is 
considered stable, the corresponding carbon emission changes brought from other effects can then be interpreted as the energy mix effect $\left(E M_{\text {effect }}\right)$, transport energy efficiency effect $\left(T E_{\text {effect }}\right)$, transport facility share effect $\left(T S_{\text {effect }}\right)$, transport usage effect $\left(T U_{\text {effect }}\right)$, transport turnover mix effect $\left(T M_{\text {effect }}\right)$, and transport turnover volume effect $\left(T V_{\text {effect }}\right)$, these represent corresponding transport-related $\mathrm{CO}_{2}$ emission changes from different factors.

We combine the potential factors that have been decomposed and the decoupling method proposed by Diakoulaki and Mandaraka [13] to detect the main drivers of decoupling status.

First, the total inhibition of $\mathrm{CO}_{2}$ emission increase is shown in the equation:

$$
\begin{aligned}
\tau(C, T V)=\Delta C- & T V_{\text {effect }} \\
& =E M_{\text {effect }}+T E_{\text {effect }}+T S_{\text {effect }}+T U_{\text {effect }}+T M_{\text {effect }}
\end{aligned}
$$

When $T V_{\text {effect }}>0$, the index of carbon emission decoupling from transport turnover volume can be defined as:

$$
\begin{array}{r}
\beta(C, T V)=-\frac{\tau(C, T V)}{T V_{\text {effect }}}=-\frac{E M_{\text {effect }}}{T V_{\text {effect }}}-\frac{T E_{\text {effect }}}{T V_{\text {effect }}}-\frac{T S_{\text {effect }}}{T V_{\text {effect }}}-\frac{T U_{\text {effect }}}{T V_{\text {effect }}}-\frac{T M_{\text {effect }}}{T V_{\text {effect }}} \\
=\beta_{E M_{\text {effect }}}+\beta_{T E_{\text {effect }}}+\beta_{T S_{\text {effect }}}+\beta_{T U_{\text {effect }}}+\beta_{T M_{\text {effect }}}
\end{array}
$$

$\beta(C, T V)$ denotes the index of carbon emission decoupling from transport turnover volume, $\beta_{E M_{\text {effect }},} \beta_{T E_{\text {effect }},} \beta_{T S_{\text {effect }}}, \beta_{T U_{\text {effect }}}$ and $\beta_{T M_{\text {effect }}}$ were the contributions to the whole decoupling process from the energy mix effect, transport efficiency effect, transport share effect, transport usage effect, transport mix effect, and transport turnover volume effect.

However, in the case of the transport turnover volume factor having a negative impact on carbon emission increase, when $T V_{\text {effect }}<0$, the index can be interpreted as:

$$
\begin{aligned}
& \beta(C, T V)=\frac{\tau(C, T V)-T V_{\text {effect }}}{T V_{\text {effect }}} \\
& \quad=\frac{E M_{\text {effect }}-T V_{\text {effect }}}{T V_{\text {effect }}}+\frac{T E_{\text {effect }}-T V_{\text {effect }}}{T V_{\text {effect }}}+\frac{T S_{\text {effect }}-T V_{\text {effect }}}{T V_{\text {effect }}} \\
&+\frac{T U_{\text {effect }}-T V_{e f f e c t}}{T V_{\text {effect }}}+\frac{T M_{\text {effect }}-T V_{\text {effect }}}{T V_{\text {effect }}}+k \\
&=\beta_{E M_{\text {effect }}}+\beta_{T E_{e f f e c t}}+\beta_{T S_{\text {effect }}}+\beta_{T U_{\text {effect }}}+\beta_{T M_{\text {effect }}}+k
\end{aligned}
$$

where $\mathrm{k}$ is a constant $(k=4)$. When $\beta(C, T V)>1$, it can be defined as a strong decoupling state, with the curbing effects being effective at cutting carbon emissions, and with the effect being even more powerful than the $\mathrm{CO}_{2}$ emission resulting from the transport output gains.

If $0<\beta(C, T V)<1$, a relative decoupling state is found. Human efforts on $\mathrm{CO}_{2}$ emission mitigation has some impact on actual $\mathrm{CO}_{2}$ emission reduction, but the $\mathrm{CO}_{2}$ emissions reduction effect is still weaker than the driving effect. In this state, the mitigation strategies have worked and cut down transport-related $\mathrm{CO}_{2}$ emissions to some degree, while the curbing effects are still not as powerful as the $\mathrm{CO}_{2}$ emissions resulting from the transport output gains.

In addition, when $\beta(C, T V)<0$, no decoupling can be tested, $\mathrm{CO}_{2}$ emission increase is in sync with transport output gains. The expected inhibiting factors do not reduce $\mathrm{CO}_{2}$ emissions in the supposed way. In other words, the $\mathrm{CO}_{2}$ emission from the expected curbing effects and the transport turnover volume both grew. Some of the promising inhabiting indictors did not work as effectively as expected. The specific effect that did not manage the target can then be determined by combining the decomposition technique after identifying $\beta_{E M_{\text {effect }}}, \beta_{T E_{\text {effect }},} \beta_{T S_{\text {effect }},} \beta_{T U_{\text {effect }}}$, and $\beta_{T M_{\text {effect }}}$.

Based on the LMDI model [52] and the modified model [53], to calculate the weight coefficient, we decompose the transport-related $\mathrm{CO}_{2}$ emission and calculate the $\mathrm{CO}_{2}$ emission changes of each influencing factor. The $\mathrm{CO}_{2}$ emission changes from the base year (the first of a series of years, year 0 ) 
to the target year (the last one of a series of years, year $t$ ) caused from each effect can be calculated by the LMDI technique, as shown in Equations (7)-(13):

$$
\begin{aligned}
& E M_{\text {effect }}=\sum_{i=1}^{3} \mu\left(C_{i}^{t}, C_{i}^{0}\right) * \ln \left(\frac{E M^{t}}{E M^{0}}\right) \\
& T E_{\text {effect }}=\sum_{i=1}^{3} \mu\left(C_{i}^{t}, C_{i}^{0}\right) * \ln \left(\frac{T E^{t}}{T E^{0}}\right) \\
& T S_{\text {effect }}=\sum_{i=1}^{3} \mu\left(C_{i}^{t}, C_{i}^{0}\right) * \sum_{j=1}^{4} \ln \left(\frac{T S_{j}^{t}}{T S_{j}^{0}}\right) \\
& =T S_{\text {effect,railways }}+T S_{\text {effect, highways }}+T S_{\text {effect,waterways }}+T S_{\text {effect,airways }} \\
& =\sum_{i=1}^{3} \mu\left(C_{i}^{t}, C_{i}^{0}\right) * \ln \left(\frac{T S_{j=1}^{t}}{T S_{j=1}^{0}}\right)+\sum_{i=1}^{3} \mu\left(C_{i}^{t}, C_{i}^{0}\right) * \ln \left(\frac{T S_{j=2}^{t}}{T S_{j=2}^{0}}\right) \\
& +\sum_{i=1}^{3} \mu\left(C_{i}^{t}, C_{i}^{0}\right) * \ln \left(\frac{T S_{j=3}^{t}}{T S_{j=3}^{0}}\right)+\sum_{i=1}^{3} \mu\left(C_{i}^{t}, C_{i}^{0}\right) * \ln \left(\frac{T S_{j=4}^{t}}{T S_{j=4}^{0}}\right) \\
& T U_{e f f e c t}=\sum_{i=1}^{3} \mu\left(C_{i}^{t}, C_{i}^{0}\right) * \sum_{j=1}^{4} \ln \left(\frac{T U_{j}^{t}}{T U_{j}^{0}}\right) \\
& =T U_{\text {effect, }, \text { railways }}+T U_{\text {effect, highways }}+T U_{\text {effect,waterways }}+T U_{\text {effect,airways }} \\
& =\sum_{i=1}^{3} \mu\left(C_{i}^{t}, C_{i}^{0}\right) * \ln \left(\frac{T U_{j=1}^{t}}{T U_{j=1}^{0}}\right)+\sum_{i=1}^{3} \mu\left(C_{i}^{t}, C_{i}^{0}\right) * \ln \left(\frac{T U_{j=2}^{t}}{T U_{j=2}^{0}}\right) \\
& +\sum_{i=1}^{3} \mu\left(C_{i}^{t}, C_{i}^{0}\right) * \ln \left(\frac{T U_{j=3}^{t}}{T U_{j=3}^{0}}\right)+\sum_{i=1}^{3} \mu\left(C_{i}^{t}, C_{i}^{0}\right) * \ln \left(\frac{T U_{j=4}^{t}}{T U_{j=4}^{0}}\right) \\
& T M_{\text {effect }}=\sum_{i=1}^{3} \mu\left(C_{i}^{t}, C_{i}^{0}\right) * \sum_{j=1}^{4} \ln \left(\frac{T M_{j}^{t}}{T M_{j}^{0}}\right) \\
& =T M_{\text {effect,railways }}+T M_{\text {effect,highways }}+T M_{\text {effect,waterways }}+T M_{\text {effect,airways }} \\
& =\sum_{i=1}^{3} \mu\left(C_{i}^{t}, C_{i}^{0}\right) * \ln \left(\frac{T M_{j=1}^{t}}{T M_{j=1}^{0}}\right)+\sum_{i=1}^{3} \mu\left(C_{i}^{t}, C_{i}^{0}\right) * \ln \left(\frac{T M_{j=2}^{t}}{T M_{j=2}^{0}}\right) \\
& +\sum_{i=1}^{3} \mu\left(C_{i}^{t}, C_{i}^{0}\right) * \ln \left(\frac{T M_{j=3}^{t}}{T M_{j=3}^{0}}\right)+\sum_{i=1}^{3} \mu\left(C_{i}^{t}, C_{i}^{0}\right) * \ln \left(\frac{T M_{j=4}^{t}}{T M_{j=4}^{0}}\right) \\
& T V_{\text {effect }}=\sum_{i=1}^{3} \mu\left(C_{i}^{t}, C_{i}^{0}\right) * \ln \left(\frac{T V^{t}}{T V^{0}}\right)
\end{aligned}
$$

where the weight coefficient $\mu\left(C_{i}^{t}, C_{i}^{0}\right)$,

$$
\mu\left(C_{i}^{t}, C_{i}^{0}\right)= \begin{cases}\frac{C_{i}^{t}-C_{i}^{0}}{\ln C_{i}^{t}-\ln C_{i}^{0}}, & C_{i}^{t} \neq C_{i}^{0} \text { and } C_{i}^{t} C_{i}^{0} \neq 0 \\ C_{i}^{0}, & C_{i}^{t}=C_{i}^{0} \\ 0, & C_{i}^{t} C_{i}^{0}=0\end{cases}
$$

$C_{i}^{t}$ and $C_{i}^{0}$ denote $\mathrm{CO}_{2}$ emission of fuel $i$ of year 0 and year $t . \quad E M_{\text {effect }}$ and $T E_{\text {effect }}$ denote $\mathrm{CO}_{2}$ emission changes from the impacts of energy mix and transport efficiency; $T S_{\text {effect }}, T U_{e f f e c t}$, $T M_{\text {effect }}$, and $T V_{\text {effect }}$ represent the contributions of the transport facility share, transport usage, transport turnover mix, and transport turnover volume effects to transport-related $\mathrm{CO}_{2}$ emission changes. It should be noted that the $\mathrm{CO}_{2}$ emission changes from the transport share effect, transport usage of per transport turnover volume, and the transport mix variation were also identified from each transport mode (railways, airways, waterways, and highways). 


\subsection{Data Management}

The transport energy consumption data of each fuel used in the paper was derived from the energy balance tables of the Chinese Energy Statistics Yearbook (CESY) [54] between 1990 and 2015. The fuel types included in this study were coal, oil, and gas; the carbon emission and energy consumption data were converted into the standard coal equivalent referring to the standard coal coefficients shown in CESY. Note that the energy consumption of transport, storage posts, and telecommunications industries was seen as a whole industry, and the share of the storage posts and telecommunications industry's energy consumption was comparatively small (7.6\% in 2007) [55], the energy use of all the stated industries were approximately considered as the energy consumption from the transport sector in this paper. The amount of transport facilities in different modes, the turnover volume of passengers and freight, were obtained from Chinese Statistics Yearbook [56] and the Transport Industry Development Statistics Bulletin [57].

\section{Results}

\section{1. $\mathrm{CO}_{2}$ Emission from Transport Sector}

The $\mathrm{CO}_{2}$ emission from transport was on the rise overall, increasing with an average annual rate of $6.65 \%$ in the last decade (2005-2015). Besides, $\mathrm{CO}_{2}$ emission growth has been accelerating since 1995. What's more, the emission changes have stepped into a new stage with a sharper increase after 2003. The turnover volume of each mode showed a growing trend despite some fluctuations. In general, air transport (green line) boomed with the highest change rate, whose average growth rate is $15.06 \% \mathrm{yr}^{-1}$, followed by road passengers and haulage (black line). In contrast, railways performed more stably than other transport modes, the turnover volume of railways only increased $4.13 \%$ per year. For airways, the turnover volume has grown over 33 times compared to the base year in 1990, indicating a huge improvement in the aviation travel mode. Also, for road travel in China, a sixteen-fold increase in the turnover ability has occurred since 1990.

As shown in Figure 2, in general, the transport turnover volume effect contributed most to the increase in transport carbon emission of $75.82 \%$, while the transport efficiency effect decreased the emission between 1990 and 2000. In the next decade, apart from energy mix changes, the other influencing factors showed more significant impacts on carbon emission, for instance, the transport efficiency effect cut $133.67 \%$ carbon emission, a great improvement compared to $16.93 \%$ in the first ten years. Relatively, the energy mix effect had minor influence on emission changes. To be more concrete, massive policy implementation on this issue may not achieve the desired effect to reduce carbon emission in the short term due to the transport efficiency improvement. The collective effect from transport share, transport usage, and transport dropped from $80.86 \%$ to $64.48 \%$, however, since the total growth in $\mathrm{CO}_{2}$ emission declined to $40.84 \%$, the collective effect was still quite significant. 


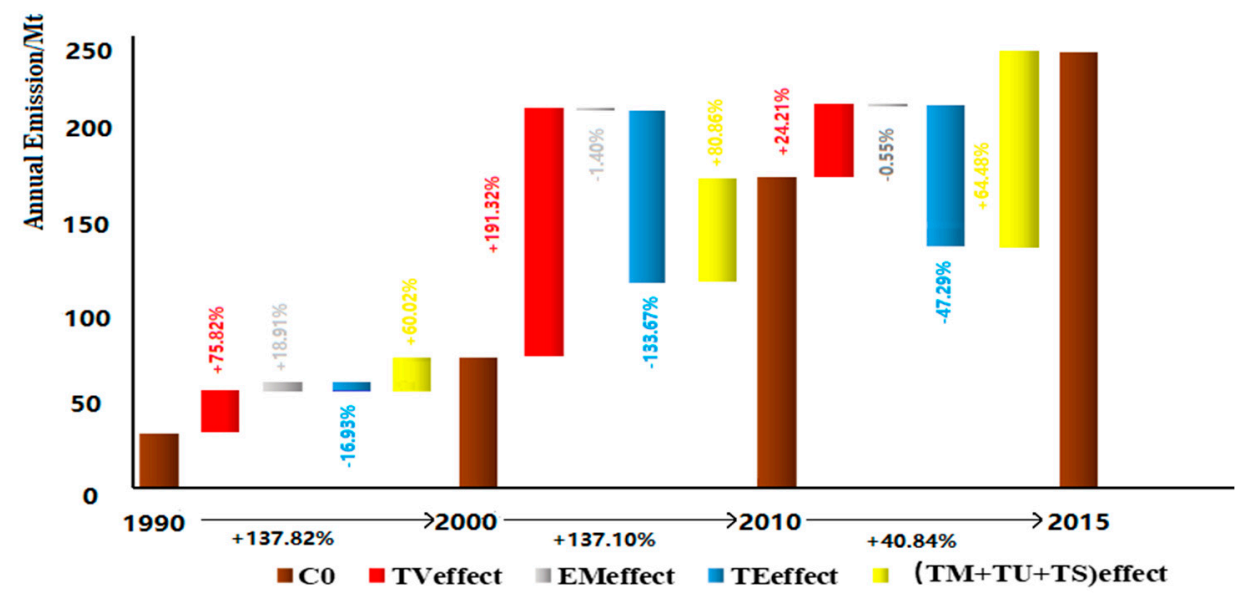

Figure 2. Annual transport-related carbon emission changes from different effects.

Apart from the overall contributions of the three effects, the specific impact of these three effects in different modes had been considered and the results are exhibited in Figure 3. For railways, both transport usage and transport mix cut down the carbon emission. $30.79 \%$ and $38.31 \%$ of the total $\mathrm{CO}_{2}$ emission changes in the first ten years were from the railways turnover volume and the number of transport locomotives. Meanwhile, the locomotive proportion of the total transport system also brought about a decrease in carbon emission. Even though 1272 more railway locomotives were put into use in railway transport, the share of the total transport facilities dropped. However, the transport mix effect showed the most significant changes to water carriage in 1990-2000, 24.06\% of the increased total $\mathrm{CO}_{2}$ emission. Also, in the first phase, the transport facilities share effect of waterways caused $216.63 \%$ of the $\mathrm{CO}_{2}$ emission, more than double the total carbon emission changes.

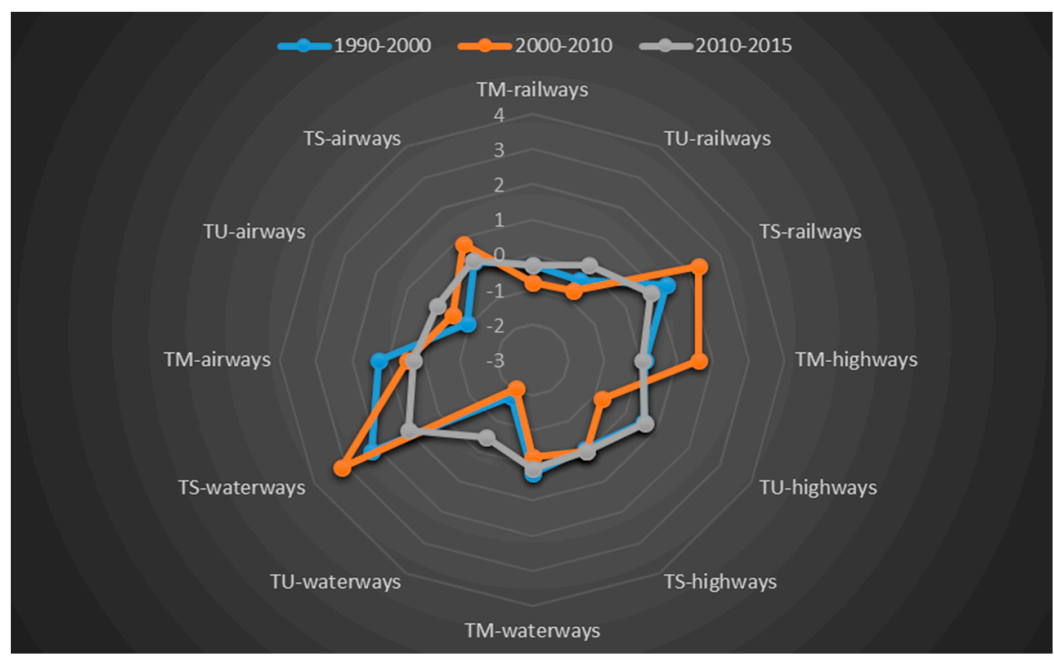

Figure 3. The modal contribution differences for three periods.

\subsection{Driver Analysis of the Transport Decoupling Index}

Overall, despite the mode differences, a weak decoupling state appeared between 1990-1995 and 2000-2010, offering empirical evidence for the decoupling of transport carbon emission from transport output. The decoupling index indicated the transport energy efficiency factor stimulated the decoupling in the observed period. The energy use of transport dropped $4.61 \% \mathrm{yr}^{-1}$, and after the year 2000 , it decreased with the annual rate of $7.02 \%$, indicating the improvement of energy use efficiency in the transport sector. Energy mix helped the decoupling. This may be because the popularity of 
transport motivated by renewable sources, such as electric cars, slowed down the transport carbon emission growth. To obtain further knowledge of the decoupling contribution from each indictor, an analysis was carried out in consideration of the character identification of different transport modes and the results are shown in Tables 4-6.

\subsubsection{Decoupling for Railways}

For railways, transport turnover mix accelerated the decoupling process and the increasingly active role of the transport turnover mix effect raised the likelihood of decoupling. Since the railways share of the total transport is the reciprocal of TS, after calculating the value of $\beta_{T S_{\text {railvays }}}$, the drop of railways locomotives' share was found to hinder the carbon emission decoupling from transport output gains. That is to say, as a low carbon emission travel mode, reducing the share of railway facilities can slow down the decoupling process. This indicates that apart from the transport energy efficiency effect accelerating the decoupling of carbon emission from transport output, for railways, the turnover ability accelerated the transport-related $\mathrm{CO}_{2}$ emission decoupling from turnover volume added. However, since the railway transport turnover volume did not compete with the growing speed of the total transport industry output, the turnover capacity should be further improved.

Table 4. The decoupling index and impacts from various factors of railways.

\begin{tabular}{cccccccc}
\hline Year & $\boldsymbol{\beta}_{T M_{\text {railvays }}}$ & $\boldsymbol{\beta}_{T U_{\text {railvays }}}$ & $\boldsymbol{\beta}_{T S_{\text {railvays }}}$ & $\boldsymbol{\beta}_{E M_{\text {effect }}}$ & $\boldsymbol{\beta}_{T E_{\text {effect }}}$ & $\boldsymbol{\beta}$ & State \\
\hline 1990-1995 & 0.14 & -0.03 & -0.20 & -0.08 & 0.17 & 0.48 & relative decoupling \\
$1995-2000$ & 0.10 & 0.37 & -0.52 & -0.82 & 0.19 & -2.03 & no decoupling \\
$2000-2005$ & 0.14 & 0.09 & -0.28 & -0.03 & 0.18 & 0.08 & relative decoupling \\
$2005-2010$ & 0.10 & 0.14 & -0.38 & 0.02 & 0.23 & 0.42 & relative decoupling \\
$2010-2015$ & 0.38 & -0.44 & -0.64 & 0.00 & 0.32 & -0.69 & no decoupling \\
\hline
\end{tabular}

\subsubsection{Decoupling for Road Transport}

As shown in Table 5, the decoupling index of the transport turnover mix effect uncovered that changes of the mix impeded the decoupling trend after 2005, however, the turnover volume share of road transport grew from $12.09 \%$ to $31.91 \%$ (Figure 4 ). Compared to an annual drop of $0.72 \%$, the sharp increase of $10.19 \% \mathrm{yr}^{-1}$ hindered the decoupling process.

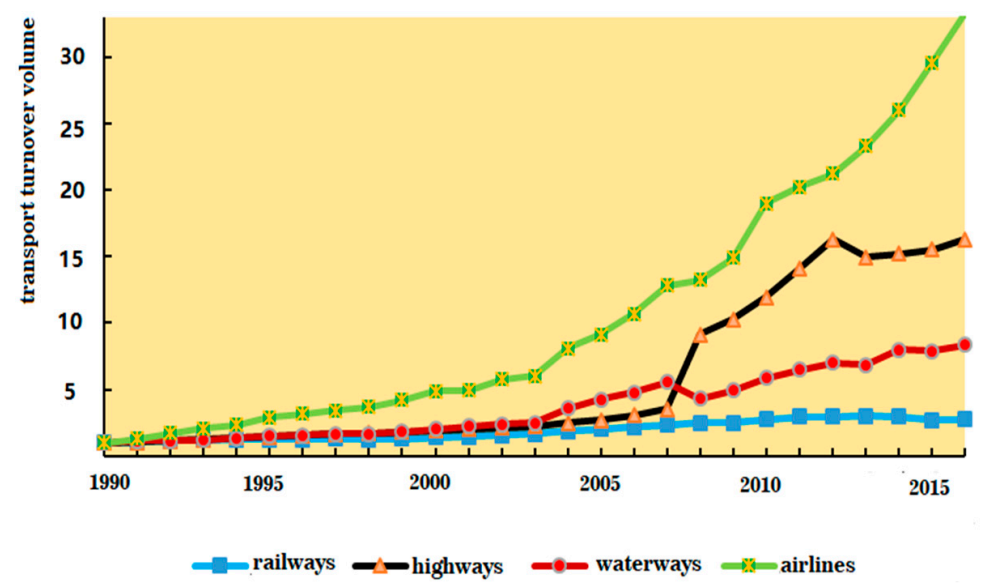

Figure 4. Trajectory of transport turnover volume of different modes. (All quantities were normalized to 1 at 1990)

$\beta_{T U_{\text {highways }}}$ was negative through all twenty-five years, indicating that vehicle usage efficiency was limited to a relatively low level and the situation has not been improved yet in the observed period. However, since more private cars were put into use and the number might be on the rise for a 
period, more research on the technology improvement related to vehicle usage efficiency is needed. In addition, the vehicle proportion of the total transport system increased while the carbon emission dropped. This may attributable to the widespread use of new electric vehicles as private cars and city buses.

Table 5. The decoupling index and impacts from various factors of road transport.

\begin{tabular}{cccccccc}
\hline Year & $\boldsymbol{\beta}_{T M_{\text {highways }}}$ & $\boldsymbol{\beta}_{T U_{\text {highways }}}$ & $\boldsymbol{\beta}_{T S_{\text {highways }}}$ & $\boldsymbol{\beta}_{E M_{\text {effect }}}$ & $\boldsymbol{\beta}_{T E_{\text {effect }}}$ & $\boldsymbol{\beta}$ & State \\
\hline 1990-1995 & 0.04 & -0.15 & 0.01 & -0.08 & 0.17 & 0.48 & relative decoupling \\
$1995-2000$ & 0.11 & -0.18 & 0.01 & -0.82 & 0.19 & -2.03 & no decoupling \\
$2000-2005$ & 0.08 & -0.14 & 0.00 & -0.03 & 0.18 & 0.08 & relative decoupling \\
$2005-2010$ & -0.01 & -0.13 & 0.00 & 0.02 & 0.23 & 0.42 & relative decoupling \\
$2010-2015$ & -0.19 & -0.52 & 0.00 & 0.00 & 0.32 & -0.69 & no decoupling \\
\hline
\end{tabular}

\subsubsection{Decoupling for Waterways}

The decoupling index of the water transport turnover mix, as demonstrated in Table 6, curbed the decoupling process, indicating that the turnover volume from waterways was still at a low level in China. The decoupling of transport usage revealed that waterways efficiency in China contributed to decoupling. The transport usage effect for water travel provided impetus for decoupling evolution, indicating that the water transport efficiency in China was positively related to the decoupling of transport carbon emission and turnover volume. According to $\beta_{T S_{\text {waterways }}}$, the transport facilities share effect of water travel hindered the decoupling process. In this case, the waterways facilities proportion of the whole transport facilities promoted the carbon emission decoupling from turnover in reverse. In other words, more ships or other water travel facilities usage within an acceptable price range can accelerate the decoupling. Therefore, a switch from high emission modes of transport to low emission modes, such as road transport to waterways, can boost transport-emission decoupling in China to some degree.

Table 6. The decoupling index and impacts from various factors of water transport.

\begin{tabular}{cccccccc}
\hline Year & $\beta_{T M_{\text {waterways }}}$ & $\beta_{T U_{\text {waterways }}}$ & $\beta_{T S_{\text {waterways }}}$ & $\beta_{E M_{\text {effect }}}$ & $\beta_{T E_{\text {effect }}}$ & $\beta$ & State \\
\hline 1990-1995 & -0.15 & 0.31 & -0.26 & -0.08 & 0.17 & 0.48 & relative decoupling \\
$1995-2000$ & -0.11 & 0.88 & -0.83 & -0.82 & 0.19 & -2.03 & no decoupling \\
$2000-2005$ & -0.10 & 0.42 & -0.37 & -0.03 & 0.18 & 0.08 & relative decoupling \\
$2005-2010$ & -0.05 & 0.33 & -0.41 & 0.02 & 0.23 & 0.42 & relative decoupling \\
$2010-2015$ & -0.03 & 0.14 & -0.82 & 0.00 & 0.32 & -0.69 & no decoupling \\
\hline
\end{tabular}

\subsubsection{Decoupling for Airways}

As is shown in Table 7 , since $\beta_{T S_{\text {airways }}}<0$, the transport facilities share effect of airways resembled the waterways, exerting a negative impact on decoupling evolution. With the expansion of air transport facilities, the decoupling process will accelerate. However, since air transport is considered a relatively carbon-intensive mode and the second largest emitter to the whole transport modes [17], the efficiency of air transport should be improved. Even though the turnover mix of air transport and transport usage effect had a distinct impact on the decoupling trend in different stages, the turnover volume of air transport increased greatly compared with other modes, especially after 2003 (shown in Figure 4). Overall, the number of aircraft per unit transport output added rose by $6.41 \%$ from 2010 to 2015 . The decoupling index of the air transport usage effect had a negative effect during this period. Future mitigation or decoupling strategies can focus on technology improvement such as energy usage improvement. 
Table 7. The decoupling index and impacts from various factors of air transport.

\begin{tabular}{cccccccc}
\hline Year & $\beta_{T M_{\text {airways }}}$ & $\beta_{T U_{\text {airways }}}$ & $\beta_{T S_{\text {airways }}}$ & $\beta_{E M_{\text {effect }}}$ & $\beta_{T E_{\text {effect }}}$ & $\beta$ & State \\
\hline 1990-1995 & -0.43 & 0.56 & -0.22 & -0.08 & 0.17 & 0.48 & relative decoupling \\
$1995-2000$ & -0.30 & 0.60 & -0.36 & -0.82 & 0.19 & -2.03 & no decoupling \\
$2000-2005$ & 0.03 & -0.03 & -0.05 & -0.03 & 0.18 & 0.08 & relative decoupling \\
$2005-2010$ & -0.19 & 0.24 & -0.19 & 0.02 & 0.23 & 0.42 & relative decoupling \\
$2010-2015$ & 9.40 & -1.12 & -0.16 & 0.05 & -3.65 & -0.69 & no decoupling \\
\hline
\end{tabular}

\section{Discussion}

In addition to focusing on economic issues, developing relevant strategies from the perspective of the transport sector, such as transport energy efficiency improvement [58], can be feasible for policy makers to break the rigid link between transport-related $\mathrm{CO}_{2}$ emission and transport output. According to the results, the transport energy mix effect primarily contributed to the decoupling process in China's transport sector, which is consistent with Dhar and Marpaung's study on Asia's transport-related $\mathrm{CO}_{2}$ emissions [59]. When decomposing, unlike most previous studies aimed at discussing influencing factors, such as population, GDP per capita, energy intensity, and emission coefficient effects, we focused more on identifying the causes from within the transportation sector. In this way, it is beneficial for the government to develop more pertinent and feasible strategies to cut down the $\mathrm{CO}_{2}$ emissions of the transport sector. After analyzing the contributions of each factor to transport-related $\mathrm{CO}_{2}$ emission changes, the transport turnover volume effect was found to be the most significant factor increasing transport-related $\mathrm{CO}_{2}$ emissions in the observed period in China. Meanwhile, the transport efficiency effect contributed to cutting down transport-related $\mathrm{CO}_{2}$ emissions, where a key element is the improvement and renovation of mitigation and energy conversion technologies. Similarly, according to Edelenbosch et al. [41], technology transition is overwhelmingly needed.

Previous decoupling studies on traffic carbon emissions primarily concentrated on the correlation analysis of $\mathrm{CO}_{2}$ emissions and economic value added. The decoupling status of transport-related $\mathrm{CO}_{2}$ emissions and economic growth has also been found [60,61]. However, because of the accelerating transport-related $\mathrm{CO}_{2}$ emissions in China, the exploration of feasible measures is in desperate need. In order to reduce transport-related $\mathrm{CO}_{2}$ emissions more effectively, pertinent mitigation strategies of the transport sector are needed, not just economic or social aspects. The relative decoupling state appeared between 1990-1995 and 2000-2010, revealing the possibility of decoupling transport-related $\mathrm{CO}_{2}$ emission from turnover volume.

Moreover, most of the studies on decoupling focus on analyzing decoupling states, and few have investigated the contribution of various factors that cause this decoupling state. But, to achieve a decoupling state now, or a possible strong decoupling state in the future, the real reason of the related decoupling states is of vital importance.

So, after testing the decoupling state in different phases, we quantified the factors' contributions to the decoupling process. Overall, railway transport was a sector with a comparatively high level of turnover capacity compared to other transport modes. After decomposing the main drivers of $\mathrm{CO}_{2}$ emissions increase from passenger cars in Greece and Denmark, a close connection between vehicle ownership and $\mathrm{CO}_{2}$ emissions was detected [37]. In our research, the transport usage effect of road transport and the vehicle proportion of all the transport facilities impeded the decoupling process, which is consistent.

According to Ang [20], the LMDI (logarithmic-mean Divisia index) method we used in this research is considered to be a preferred approach because of its ease of use and adaptability. Also, unlike the hypotheses or ideal conditions that must be made before applying econometric models, the LMDI method can be adapted with no strict prerequisites. Yet, there are some questions we cannot address thoroughly at the moment. Not all the possible factors can be analyzed due to the limit of the Kaya identity (must be divided into several multiplications). We can only select the main factors to 
carry out our research on the basis of a detailed review of the previous studies related to the same topic. In future work, we will deepen our research by considering more spatial issues, such as spatially stratified heterogeneity. To achieve the ultimate goal of sustainability in the transport sector, technology improvement and switching are currently considered significant and effective measures.

\section{Conclusions and Policy Implications}

This paper chose China as an empirical case to analyze the decoupling possibility of transport-related $\mathrm{CO}_{2}$ emissions from transport turnover volume. The transport decoupling states of different travel modes in China were identified from the perspective of each mode's characteristics and the decoupling decomposition analyses were carried out, respectively. In brief, some conclusions and relevant policy implications to promote the decoupling evolution are stated:

Transport-related $\mathrm{CO}_{2}$ emissions have increased and carbon emission growth has accelerated since 1995. Among all the drivers, the transport turnover volume effect was the primary driver of carbon emission growth in the transport industry in China, while the transport efficiency effect cut down the transport-related $\mathrm{CO}_{2}$ emissions. The technology of energy use in the transport industry should focus more on energy efficiency improvement. Also, with the rise in car ownership in recent years, developing strategies for changing passengers' travelling behavior should be considered. For example, offering convenient and affordable public transit solutions. In general, the transport energy efficiency effect reduced the transport-related carbon emissions during the observed period. The railway turnover mix decreased carbon emissions, while road and air transport added more $\mathrm{CO}_{2}$ emissions. Apart from the vehicle share of the transport facilities increasing the $\mathrm{CO}_{2}$ emission, all the other travel modes put a brake on emission growth. Consequently, modal replacement strategies should be encouraged to foster $\mathrm{CO}_{2}$ emission mitigation.

Relative decoupling states appeared between 1990-1995 and 2000-2010 in China, indicating the possibility that transport-related $\mathrm{CO}_{2}$ emission decoupling from turnover volume gains is possible, giving empirical evidence for other countries. Overall, the transport energy efficiency effect contributed the most in advancing the transport-related $\mathrm{CO}_{2}$ emission decoupling from turnover volume for all transport modes, while the energy mix effect hindered the decoupling process in most observed periods. Apart from road transport, the proportion of other travel modes' growth can boost decoupling. The transport usage effect of road transport and the vehicle proportion of transport facilities impeded the decoupling process. Since the bike-sharing systems in China has been set up [62], the shared transport system of other travel modes can be explored. For the decoupling evolution, railway transport was a sector with a relatively high level of turnover capacity, advancing the railways carbon emission decoupling from all the transport industry output gains.

For railways, transport turnover mix and railways locomotives share rises can boost the decoupling evolution. Since the 1990s, rail-transport has been steadily replaced by vehicles in China. Locomotive ownership increased by $1.64 \% \mathrm{yr}^{-1}$, rather slow compared to $22.88 \% \mathrm{yr}^{-1}$ for private cars. Thus, revitalizing the railways within acceptable expenses should be considered. For instance, in addition to the continuous energy efficiency improvement, pouring more money to railway turnover technology innovations should be encouraged.

The changes of the vehicles turnover mix impeded the decoupling after 2005 in China. Because of the sharp rise of private cars, the decoupling has slowed. Since the private vehicles proportion of civil vehicles in China grew from $14.80 \%$ in 1990 to $87.92 \%$ in 2015, more incentives to encourage travel mode switching should be provided. Besides infrastructure improvement, price policies concerning road transport, such as levying more taxes on road maintenance, parking, or insurance should also be considered. What's more, the "Smart Growth" development pattern [63] can be adopted, for example, the Bus Rapid Transit (BRT) system can be promoted further to replace current individual car-oriented travel choices.

The water transport turnover mix hindered the decoupling evolution, while the waterways transport usage effect stimulated transport-related $\mathrm{CO}_{2}$ emission decoupling from turnover volume. 
Likewise, the rising proportion of waterways facilities promoted the carbon emission decoupling from turnover in China in the observed years. With the increase in air transport facilities proportion, the decoupling process from transport output will accelerate. The turnover mix of air transport and the transport usage effect had a distinct impact on the decoupling trend in different stages. According to Loo and Li [17], water transport can be a low carbon emission transport mode, whereas air transport is the second largest contributor to transport-related carbon emissions. Meanwhile, with the limits of funding and sustainable technology, policies should combine economic and environmental systems to achieve the decoupling goal.

Author Contributions: X.-t.J. conceived and designed the experiments, performed the experiments, analyzed the data and wrote the paper; M.S. and R.L. contributed reagents/materials/analysis tools. All authors read and approved the final manuscript.

Funding: The current work is supported by fund from CAS Research Center for Ecology and Environment of Central Asia (1100002436).

Conflicts of Interest: The authors declare no conflict of interest.

\section{References}

1. IEA. $\mathrm{CO}_{2}$ Emissions from Fuel Combustion; International Energy Agency: Paris, France, 2017.

2. Wang, Q.; Chen, X. Energy policies for managing China's carbon emission. Renew. Sust. Energ. Rev. 2015, 50, 470-479. [CrossRef]

3. Wang, Q. China should aim for a total cap on emissions. Nature 2014, 512, 115. [CrossRef] [PubMed]

4. Li, R.R.; Su, M. The role of natural gas and renewable energy in curbing carbon emission: Case study of the United States. Sustainability 2017, 9, 600. Available online: http:/ /www.mdpi.com/2071-1050/9/4/600 (accessed on 15 August 2018). [CrossRef]

5. Wang, Q.; Zhao, M.; Li, R.; Su, M. Decomposition and decoupling analysis of carbon emissions from economic growth: A comparative study of China and the United States of America. J. Clean. Prod. 2018, 197, 178-184. [CrossRef]

6. Jiang, R.; Zhou, Y.; Li, R. Moving to a Low-Carbon Economy in China: Decoupling and Decomposition Analysis of Emission and Economy from a Sector Perspective. Sustainability 2018, 10, 978. Available online: www.mdpi.com/2071-1050/10/4/978/pdf (accessed on 15 August 2018). [CrossRef]

7. Wang, Q.; Jiang, R.; Li, R. Decoupling analysis of economic growth from water use in City: A case study of Beijing, Shanghai, and Guangzhou of China. Sustain. Cities Soc. 2018, 41, 86-94. [CrossRef]

8. Wang, Q.; Chen, X.; Yi-chong, X. Accident like the Fukushima unlikely in a country with effective nuclear regulation: Literature review and proposed guidelines. Renew. Sustain. Energy Rev. 2013, 17, 126-146. [CrossRef]

9. Weizsäcker, E.U.V. Erdpolitik: Ökologische Realpolitik an der Schwelle zum Jahrhundert der Umwelt; Wissenschaftliche Buchgesellschaft: Darmstadt, Germany, 1990.

10. Zhang, Z. Decoupling China's Carbon Emissions Increase from Economic Growth: An Economic Analysis and Policy Implications. World Dev. 2000, 28, 739-752. [CrossRef]

11. Ruefing, K. Indicators to Measure Decoupling of Environmental Pressure from Economic Growth; Island Press: Washington, DC, USA, 2007; pp. 211-222.

12. Tapio, P. Towards a theory of decoupling: Degrees of decoupling in the EU and the case of road traffic in Finland between 1970 and 2001. Transp. Policy 2005, 12, 137-151. [CrossRef]

13. Diakoulaki, D.; Mandaraka, M. Decomposition analysis for assessing the progress in decoupling industrial growth from $\mathrm{CO}_{2}$ emissions in the EU manufacturing sector. Energy Econ. 2007, 29, 636-664. [CrossRef]

14. Loo, B.P.Y.; Banister, D. Decoupling transport from economic growth: Extending the debate to include environmental and social externalities. J. Transp. Geogr. 2016, 57, 134-144. [CrossRef]

15. Alises, A.; Vassallo, J.M.; Guzmán, A.F. Road freight transport decoupling: A comparative analysis between the United Kingdom and Spain. Transp. Policy 2014, 32, 186-193. [CrossRef]

16. He, K.; Huo, H.; Zhang, Q.; He, D.; An, F.; Wang, M.; Walsh, M.P. Oil consumption and $\mathrm{CO}_{2}$ emissions in China's road transport: Current status, future trends, and policy implications. Energy Policy 2005, 33, 1499-1507. [CrossRef] 
17. Loo, B.P.Y.; Li, L. Carbon dioxide emissions from passenger transport in China since 1949: Implications for developing sustainable transport. Energy Policy 2012, 50, 464-476. [CrossRef]

18. Wang, Q.; Jiang, X.-t.; Li, R. Comparative decoupling analysis of energy-related carbon emission from electric output of electricity sector in Shandong Province, China. Energy 2017, 127, 78-88. [CrossRef]

19. Ang, B.W.; Goh, T. Bridging the gap between energy-to-GDP ratio and composite energy intensity index. Energy Policy 2018, 119, 105-112. [CrossRef]

20. Ang, B.W. Decomposition analysis for policymaking in energy: Which is the preferred method? Energy Policy 2004, 32, 1131-1139. [CrossRef]

21. Wang, Q.; Li, R. Journey to burning half of global coal: Trajectory and drivers of China's coal use. Renew. Sustain. Energy Rev. 2016, 58, 341-346. [CrossRef]

22. Ehrlich, P.R.; Holdren, J.P. Impact of Population Growth. Science 1971, 171, 1212. Available online: http:/ / www.jstor.org/stable/1731166 (accessed on 17 August 2018). [CrossRef] [PubMed]

23. Kaya, Y. Impact of Carbon Dioxide Emission Control on GNP Growth: Interpretation of Proposed Scenarios; Paper presented the IPCC Energy and Industry Subgroup; Response Strategies Working Group: Paris, France, 1990.

24. Dietz, T.; Rosa, E.A. Rethinking the environmental impacts of population, Affluence and technology. Hum. Ecol. Rev. 1994, 1, 277-300. [CrossRef]

25. Rose, A.; Casier, S. Input-Output Structural Decomposition Analysis: A Critical Appraisal. Econ. Syst. Res. 1996, 8, 33-62. [CrossRef]

26. Dietz, T.; Rosa, E.A. Effects of Population and Affluence on $\mathrm{CO}_{2}$ Emissions. Proc. Natl. Acad. Sci. USA 1997, 94, 175-179. [CrossRef] [PubMed]

27. Leontief, W. Environmental Repercussions and the Economic Structure: An Input-Output Approach. Rev. Econ. Stat. 1970, 56, 109-110. [CrossRef]

28. Dietzenbacher, E.; Los, B. Structural Decomposition Techniques: Sense and Sensitivity. Econ. Syst. Res. 1998, 10, 307-324. [CrossRef]

29. Su, B.; Ang, B.W. Structural decomposition analysis applied to energy and emissions: Some methodological developments. Energy Econ. 2012, 34, 177-188. [CrossRef]

30. Liao, C.H.; Lu, C.S.; Tseng, P.H. Carbon dioxide emissions and inland container transport in Taiwan. J. Transp. Geogr. 2011, 19, 722-728. [CrossRef]

31. Zhang, C.; Nian, J. Panel estimation for transport sector $\mathrm{CO}_{2}$ emissions and its affecting factors: A regional analysis in China. Energy Policy 2013, 63, 918-926. [CrossRef]

32. Paravantis, J.A.; Georgakellos, D.A. Trends in energy consumption and carbon dioxide emissions of passenger cars and buses. Technol. Forecast. Soc. Chang. 2007, 74, 682-707. [CrossRef]

33. Shakya, S.R.; Shrestha, R.M. Transport sector electrification in a hydropower resource rich developing country: Energy security, environmental and climate change co-benefits. Energy Sustain. Dev. 2011, 15, 147-159. [CrossRef]

34. Graham, D.J.; Crotte, A.; Anderson, R.J. A dynamic panel analysis of urban metro demand. Transp. Res. Part E Logist. Transp. Rev. 2009, 45, 787-794. [CrossRef]

35. Simões, A.F.; Schaeffer, R. The Brazilian air transportation sector in the context of global climate change: $\mathrm{CO}_{2}$ emissions and mitigation alternatives. Energy Convers. Manag. 2005, 46, 501-513. [CrossRef]

36. Scholl, L.; Schipper, L.; Kiang, N. $\mathrm{CO}_{2}$ emissions from passenger transport: A comparison of international trends from 1973 to 1992. Energy Policy 1996, 24, 17-30. [CrossRef]

37. Papagiannaki, K.; Diakoulaki, D. Decomposition analysis of $\mathrm{CO}_{2}$ emissions from passenger cars: The cases of Greece and Denmark. Energy Policy 2009, 37, 3259-3267. [CrossRef]

38. Achour, H.; Belloumi, M. Decomposing the influencing factors of energy consumption in Tunisian transportation sector using the LMDI method. Transp. Policy 2016, 52, 64-71. [CrossRef]

39. Feng, T.-T.; Yang, Y.-S.; Xie, S.-Y.; Dong, J.; Ding, L. Economic drivers of greenhouse gas emissions in China. Renew. Sustain. Energy Rev. 2017, 78, 996-1006. [CrossRef]

40. Luo, X.; Dong, L.; Dou, Y.; Li, Y.; Liu, K.; Ren, J.; Liang, H.; Mai, X. Factor decomposition analysis and causal mechanism investigation on urban transport $\mathrm{CO}_{2}$ emissions: Comparative study on Shanghai and Tokyo. Energy Policy 2017, 107, 658-668. [CrossRef] 
41. Edelenbosch, O.Y.; McCollum, D.L.; van Vuuren, D.P.; Bertram, C.; Carrara, S.; Daly, H.; Fujimori, S.; Kitous, A.; Kyle, P.; Ó Broin, E.; et al. Decomposing passenger transport futures: Comparing results of global integrated assessment models. Transp. Res. Part D Transp. Environ. 2017, 55, 281-293. [CrossRef]

42. Andrés, L.; Padilla, E. Driving factors of GHG emissions in the EU transport activity. Transp. Policy 2018, 61, 60-74. [CrossRef]

43. Schipper, L.; Steiner, R.; Duerr, P.; An, F.; Strøm, S. Energy use in passenger transport in OECD countries: Changes since 1970. Transportation 1992, 19, 25-42. [CrossRef]

44. Danielis, R. Energy use for transport in Italy: Past trends. Energy Policy 1995, 23, 799-807. [CrossRef]

45. Kiang, N.; Schipper, L. Energy trends in the Japanese transportation sector. Transp. Policy 1996, 3, $21-35$. [CrossRef]

46. Greening, L.A.; Ting, M.; Davis, W.B. Decomposition of aggregate carbon intensity for freight: Trends from 10 OECD countries for the period 1971-1993. Energy Econ. 1999, 21, 331-361. [CrossRef]

47. Kwon, T.-H. Decomposition of factors determining the trend of $\mathrm{CO}_{2}$ emissions from car travel in Great Britain (1970-2000). Ecol. Econ. 2005, 53, 261-275. [CrossRef]

48. Sobrino, N.; Monzon, A. The impact of the economic crisis and policy actions on GHG emissions from road transport in Spain. Energy Policy 2014, 74, 486-498. [CrossRef]

49. IPCC. Greenhouse Gas Inventory: IPCC Guidelines for National Greenhouse Gas Inventories; IPCC: Bracknell, UK, 2006.

50. National Development and Reform Commission. China's Sustainable Development Energy and Carbon Emission Scenarios. 2003. Available online: http:/ / www.efchina.org/Attachments/Report/reports-efchina20061209-6-zh/Fnl_Scenario_CN.pdf (accessed on 17 August 2018). (In Chinese)

51. CAS Sustainable Development Strategy Team. China's Sustainable Development Strategy Report in 2009; Science Press: Beijing, China, 2009.

52. Ang, B.W.; Liu, F.L.; Chew, E.P. Perfect decomposition techniques in energy and environmental analysis. Energy Policy 2003, 31, 1561-1566. [CrossRef]

53. Wang, Q.; Li, S.; Li, R.; Ma, M. Forecasting U.S. shale gas monthly production using a hybrid ARIMA and metabolic nonlinear grey model. Energy 2018, 160, 378-387. [CrossRef]

54. National Bureau of Statistics. Chinese Energy Statistics Yearbook 2016; China Statistics Press: Beijing, China, 2016.

55. Fan, F.; Lei, Y. Decomposition analysis of energy-related carbon emissions from the transportation sector in Beijing. Transp. Res. Part D Transp. Environ. 2016, 42, 135-145. [CrossRef]

56. National Bureau of Statistics. Chinese Statistics Yearbook 2017; China Statistics Press: Beijing, China, 2017.

57. Ministry of Transport of the People's Republic of China: Transport Industry Development Statistics Bulletin (2015). 2016. Available online: http://zizhan.mot.gov.cn/zfxxgk/bnssj/zhghs/201605/t20160506_2024006. html (accessed on 17 August 2018). (In Chinese)

58. Xu, B.; Lin, B. Carbon dioxide emissions reduction in China's transport sector: A dynamic VAR (vector autoregression) approach. Energy 2015, 83, 486-495. [CrossRef]

59. Dhar, S.; Marpaung, C.O.P. Technology priorities for transport in Asia: Assessment of economy-wide $\mathrm{CO}_{2}$ emissions reduction for Lebanon. Clim. Chang. 2015, 131, 451-464. [CrossRef]

60. Roinioti, A.; Koroneos, $\mathrm{C}$. The decomposition of $\mathrm{CO}_{2}$ emissions from energy use in Greece before and during the economic crisis and their decoupling from economic growth. Renew. Sustain. Energy Rev. 2017, 76, 448-459. [CrossRef]

61. Wang, Y.; Xie, T.; Yang, S. Carbon emission and its decoupling research of transportation in Jiangsu Province. J. Clean. Prod. 2017, 142, 907-914. [CrossRef]

62. The Guardian Uber for Bikes: How 'Dockless' Cycles Flooded China-And Are Heading Overseas. Available online: https:/ / www.theguardian.com/cities/2017/mar/22/bike-wars-dockless-china-millionsbicycles-hangzhou (accessed on 11 April 2018).

63. Houdashelt, M. Reducing Transportation Emissions: Travel Demand Measures; Center for Clean Air Policy: Paris, France, 2006.

(c) 2018 by the authors. Licensee MDPI, Basel, Switzerland. This article is an open access article distributed under the terms and conditions of the Creative Commons Attribution (CC BY) license (http:/ / creativecommons.org/licenses/by/4.0/). 